\title{
TURISMO RELIGIOSO, TERRITÓRIO E TERRITORIALIDADES: o Círio de Nazaré em Belém-PA ${ }^{1}$ TOURISME RELIGIEUX, TERRITOIRE ET TERRITORIALITÉ: le Cirio de Nazaré à Belém do Pará
}

\section{Resumo}

\author{
Débora Rodrigues de Oliveira Serra \\ Companhia Paraense de Turismo \\ debserra1980@hotmail.com
}

O presente artigo trata de uma abordagem teórica e empírica sobre o processo de turistificação do espaço no Círio de Nazaré em Belém na perspectiva do segmento do turismo religioso, envolvendo questões vinculadas a território e territorialidades. A metodologia utilizada constituiu-se de levantamento bibliográfico acerca da relação entre turismo, principalmente o religioso, territórios e territorialidades, bem como quanto ao referido evento, para o qual se somaram as observações empíricas. $\mathrm{O}$ estudo demonstra a importância da abordagem territorial para o turismo e para os processos de turistificação de espaços ligados ao turismo religioso.

Palavras-chave: território, territorialidades, turistificação, turismo religioso, Círio de Nazaré.

\section{Résumé}

Cet article s'agit d'un aproche théorique et empirique du processus de touristification de Cirio de Nazaré à Belém, du point de vue du segment tourisme religieux, sur des questions relatives au territoire et territorialité. La méthodologie utilisée, s'est constituée de la literature bibliographique sur le rapport entre tourisme - surtout le religieux territoires et territorialité, aussi comme cet évenement, pour le quel se sont ajoutées les observations empiriques. L'étude présente l'importance de l'approche territoriale pour le tourisme et pour les proccès de touristification des zones liées aux tourisme réligieux.

Mots-clés: territoire, territorialité, touristification, le tourisme religieux, Cirio de Nazaré

\section{INTRODUÇÃO}

\footnotetext{
${ }^{1}$ Artigo resultado de pesquisas em desenvolvimento no Programa de Pós Graduação em Geografia da Universidade Federal do Pará sob orientação da Prof ${ }^{a}$. Drª . Maria Goretti da Costa Tavares.

Geo UERJ - Ano 15, no. 24, v. 1, $1^{\circ}$ semestre de 2013 p. 104-124

ISSN: 1415-7543 E-ISSN: 1981-9021

http://www.e-publicacoes.uerj.br/index.php/geouerj
} 
O Círio de Nazaré em Belém do Pará é realizado desde o final do século XVIII, e ao longo dos anos tornou-se um complexo de eventos sagrados e profanos, atraindo de modo crescente milhares de turistas para a cidade no mês de outubro.

Observando-se a importância dessa festividade para a atividade turística, o presente artigo visa abordá-lo teórica e empiricamente a partir dos estudos de Fratucci (2008) referentes à turistificação de espaços e os agentes envolvidos nesse processo. As discussões sobre o turismo religioso e sua relação com questões territoriais também contribuem para essa análise.

Para isso, foi necessário um levantamento bibliográfico acerca da relação entre turismo e território (principalmente no que se refere ao segmento do turismo religioso) e da festividade do Círio de Nazaré, para a qual se somaram as observações empíricas.

Assim, este artigo abordará inicialmente a relação entre turismo e território, enfocando os agentes do processo turistificação do espaço e a importância dessa categoria de análise geográfica para a atividade turística, ainda carecendo, no Brasil, de políticas claras em relação ao seu ordenamento territorial. Em seguida tratar-se-á de considerações relativas ao turismo e território religioso, bem como a conflitos entre territorialidades sagradas e profanas. Por fim, o Círio de Nazaré em Belém será abordado como um complexo de eventos no qual ocorre a atuação de diversos agentes que têm contribuído para a turistificação dessa festividade.

\section{TURISMO E TERRITÓRIO: A APROPRIAÇÃO DOS ESPAÇOS PARA O TURISMO}

Apesar de diversos estudiosos e das políticas públicas abordarem o turismo sobretudo por sua dimensão econômica, ele se trata de um fenômeno complexo, por ser também uma prática social, visto que ocorre a partir do deslocamento do turista de seu local de origem para um destino onde serão estabelecidas relações entre ele e os anfitriões. Para Cruz (2007), além de atividade econômica, o turismo é também uma atividade produtiva, considerando-se que ele transforma o espaço em mercadoria inserindo-o no circuito de troca.

Geo UERJ - Ano 15, nº. 24, v. 1, $1^{\circ}$ semestre de 2013 p. 104-124

ISSN: 1415-7543 E-ISSN: 1981-9021

http://www.e-publicacoes.uerj.br/index.php/geouerj 
Por tal complexidade, o turismo é estudado por diversas ciências, e, desta forma, não podemos eleger uma única definição para esta atividade. Porém as definições em geral apontam para necessidade do deslocamento, o tempo de duração da viagem e as motivações. Castro (2006) observa que as definições

\footnotetext{
permitem identificar os quatro elementos essenciais ao turismo: os turistas; os mecanismos públicos e privados de ordenamento da atividade; os meios e a infraestrutura de transportes responsáveis pela mobilidade dos turistas e a destinação turística que oferece a comunidade anfitriã; o(s) produto(s) que se constituirão em atratividade e a infraestrutura de serviços necessários (p. 42).
}

A atividade turística apresenta um caráter territorial, que segundo Ivars apud Silva (2004), é determinado pelo deslocamento que as pessoas fazem de seu lugar de origem até o destino turístico, ou seja, espaços que concentram atrativos e condições que satisfaçam o turista de acordo com suas motivações. Tais deslocamentos (os fluxos turísticos) provocam diversos efeitos sobre os territórios, tanto positivos, quanto negativos, de acordo com as intencionalidades dos agentes.

Visando a compreensão da relação entre o turismo e o território, é necessário refletir sobre tal categoria geográfica e, assim, pode-se destacar a concepção integradora de Haesbaert (2004), em sua discussão sobre a multiterritorialidade. Para ele, esta categoria contém relações de dominação e/ou de apropriação e "desdobra-se ao longo de um continuum que vai da dominação político-econômica mais 'concreta' e 'funcional' à apropriação mais subjetiva e/ou 'cultural-simbólica' ,'(p. 95-96). Tal concepção integra as perspectivas materialistas e idealistas dando importância tanto ao poder político-econômico quanto ao simbólico.

Para tratar posteriormente do turismo religioso, em especial aquele relativo às festividades religiosas, como o Círio de Nazaré, considera-se importante também o destaque para a expressão “território móvel” proposta por Souza (2003) ao observar que os territórios podem ou não ter um caráter permanente. Para ele os territórios são "antes relações sociais projetadas no espaço que espaços concretos (...)" podendo "formar-se e dissolver-se, constituir-se e dissipar-se de modo relativamente rápido (...) e isto apesar de que o substrato espacial permanece ou pode permanecer o mesmo" (2003, p. 87).

Geo UERJ - Ano 15, nº. 24, v. 1, $1^{\circ}$ semestre de 2013 p. 104-124

ISSN: 1415-7543 E-ISSN: 1981-9021

http://www.e-publicacoes.uerj.br/index.php/geouerj 
Essa expressão é incluída nos estudos de Haesbaert (2004) como parte da multiplicidade de territorializações que ocorre ao mesmo tempo em todo o planeta, chamando-as de "territorializações mais flexíveis" onde ocorrem tanto a sobreposição territorial como a intercalação de territórios.

Buscando abordar cientificamente a atividade turística, Knafou (1996) tratou das relações entre turismo e território apontando três possibilidades: os territórios sem turismo, o turismo sem território e os territórios turísticos.

Os territórios sem turismo eram comuns até o que o autor coloca como “invenção" do turismo no século XVIII na Europa, mas com as facilidades de acesso pelo desenvolvimento dos transportes, eles seriam cada vez mais raros. O turismo sem território se refere àquele que não resulta da iniciativa dos turistas, mas sim de operadores turísticos, onde os turistas não se apropriam do espaço, construídos geralmente em lugares de passagem tal como os "Center Parcs" criados no noroeste da Europa. Já os territórios turísticos seriam aqueles criados pelos turistas e de certa forma retomados pelos operadores e planejadores da atividade.

Para Queiroz (2005), há também um quarto tipo de relação: os territórios compartidos com o turismo, referindo-se à apropriação, pelo turismo, de espaços “já ocupados ou delineados para outras atividades, a exemplo de cidades cujo território não pode ser considerado exclusivamente turístico" (p. 172).

Nesse sentido, acrescenta-se que para Cruz (2007), a expressão "território turístico" não existe teoricamente, mas sim os "usos turísticos do território" uma vez que a apropriação de porções dos espaços ocorre por diversas atividades ao mesmo tempo, incluindo-se e destacando-se em alguns casos o turismo.

Tal afirmação pode ser observada empiricamente no contexto de festas religiosas a exemplo do Círio de Nazaré em Belém, visto que apesar de sua importância como atrativo turístico, os espaços utilizados para a sua realização são apropriados por agentes de diversas atividades, desde religiosas a comerciais, e que não necessariamente vinculam-se à atividade turística.

A abordagem territorial da atividade turística está relacionada com os processos de turistificação do espaço uma vez que ela é consumidora de porções do espaço consideradas privilegiadas, que são apropriados pelos seus agentes sociais. 
Nesse sentido, relacionando-se com a definição de território proposta por Haesbaert (2004) apresentada anteriormente, Fratucci (2008) afirma que:

\footnotetext{
O processo de turistificação dos espaços (...) compreende tanto o processo de apropriação simbólica de trechos do espaço pelo turista (a partir de "olhares" diferenciados social, política e culturalmente), como o processo de dominação pelos agentes econômicos e pelos agentes de governo (p.53).
}

Além dos turistas, agentes econômicos (ou de mercado) e agentes de governo (o Estado), Fratucci (2008) inclui as comunidades receptoras dentre os agentes de turistificação dos espaços, considerando-se que de acordo com suas características, necessidades e expectativas, e agindo e interagindo sincronicamente, todos eles podem interferir no curso da atividade turística.

Para ele, o turista é o agente social gerador do fenômeno que se desterritorializa temporariamente a partir do seu deslocamento para outros pontos do espaço por motivações diversas, produzindo, desta forma, territórios mais fluidos e sazonais, além de movimentar a cadeia econômica ligada à satisfação de suas necessidades.

Ao tratar dos agentes de mercado ou do trade turístico, o autor afirma que, com as necessidades dos turistas e por meio dos empresários, o capital mercantilizou o fenômeno turístico transformando-o em mais uma atividade econômica. Tais necessidades permitem a divisão desses agentes entre os que se relacionam diretamente com os turistas (proprietários de meios de hospedagem, restaurantes, transportadoras, etc) e os indiretamente relacionados (empresários do ramo de comunicação, segurança, fornecedores de insumos, etc.).

Ao Estado, em seus diferentes níveis de governo, cabe a normatização e regulação da atividade de modo a atender os interesses da população local atentando ao mesmo tempo para a lógica do capital.

A comunidade receptora, geralmente ignorada pelos estudiosos como um agente de turistificação, foi agrupada por Fratucci entre os que trabalham diretamente na atividade turística, os trabalhadores indiretos e a população residente não envolvida com o turismo.

Geo UERJ - Ano 15, nº. 24, v. 1, $1^{\circ}$ semestre de 2013 p. 104-124

ISSN: $1415-7543$ E-ISSN: 1981-9021

http://www.e-publicacoes.uerj.br/index.php/geouerj 
É necessário observar que tais agentes atuam em maior ou menor grau nos processos de turistificação e de acordo com Cruz (2007), em seu estudo sobre o turismo como uma das atividades produtoras de espaço, os agentes hegemônicos seriam o Estado e o mercado, tendo muitas vezes o primeiro uma postura de subserviência em relação ao segundo. Ela acrescenta, porém, que "a hegemonia de um ou de outro não anula as possibilidades de contramovimentos" referindo-se às reações da sociedade civil organizada. E completa a discussão sobre a hegemonia dos agentes reconhecendo o papel dos turistas tanto por serem a razão da atuação do Estado e do mercado, como por serem responsáveis pela invenção de muitos destinos turísticos.

Com base em Vera Rebollo, Queiroz (2005) ressalta que devido à importância do território para o turismo e dado o alto grau de competitividade entre os destinos turísticos, a ordenação e a gestão territorial são fundamentais. E, nesse sentido, a utilização racional do território a partir da planificação territorial "torna-se imprescindível àquelas áreas que almejam conquistar ou manter alguma hegemonia no contexto de mercados e lugares globalizados" (p.173).

$\mathrm{O}$ ordenamento territorial como conceito tem sido discutido por diversos autores e, embora passível de críticas, de acordo com Rückert (2005), há a definição a Carta Europeia de Ordenação do Território:

\footnotetext{
A expressão espacial das políticas econômicas, sociais, culturais e ecológicas da sociedade. É uma disciplina científica, uma técnica administrativa e uma política concebida com um enfoque interdisciplinar e global, cujo objetivo é um desenvolvimento equilibrado das regiões e da organização física do espaço segundo um conceito diretor (p.34).
}

Retomando a discussão sobre o Estado como agente do processo de turistificação, sua importância perpassa pelo seu papel regulador e definidor de políticas de ordenamento territorial, e desta forma, destaca-se no Brasil a construção da Política Nacional de Ordenamento Territorial, iniciada a partir de 2003 pelo Ministério da Integração Nacional.

Em relação ao turismo, Ferreira (2009) apresenta a evolução das políticas públicas para esta atividade desde a década de 1970, com a criação da EMBRATUR até 
a criação do Ministério de Turismo e a formulação dos Planos Nacionais de Turismo (PNT) nas versões 2003/2007 e 2007/2010. A autora afirma que apesar do PNT 2007/2010 não especificar propostas de ordenamento territorial para o turismo, a proposta de desconcentração do turismo das áreas litorâneas bem como a diversificação do produto turístico podem ser considerados como as principais diretrizes de ordenamento territorial da atividade. Tais propostas permitem que os diversos municípios tenham autonomia para desenvolver a atividade considerando-se suas especificidades paisagísticas e socioculturais.

A proposta de diversificação do produto turístico possibilita que os vários segmentos da atividade, dentre eles o turismo religioso, sejam considerados passíveis de investimentos pelos diversos agentes.

\section{TURISMO RELIGIOSO: TERRITÓRIOS, TERRITORIALIDADES E CONFLITOS ENTRE O SAGRADO E O PROFANO}

Devido à intensa proximidade entre os segmentos do turismo religioso e do cultural, o Ministério do Turismo, em seus cadernos referentes às segmentações da atividade, considera que o religioso trata-se de um dos tipos de turismo cultural, mas que decorre "da busca espiritual e da prática religiosa em espaços e eventos relacionados às religiões institucionalizadas (...)" (BRASIL, 2010, p.19). Entretanto, o referido Ministério considera apenas como turismo cultural a experiência realizada por turistas que viajam para eventos ou espaços religiosos tendo como motivação o interesse cultural ou a apreciação estética, ou seja, sem a busca pela prática religiosa.

Para além da discussão sobre a relação entre o turismo religioso e o cultural, observa-se também a ênfase dada à religião católica quando se trata desse segmento. Nesse sentido, Dechandt (2011), propõe o termo turismo em lugares de grande densidade religiosa, pois, entre outras razões pressupõe "a coincidência da expressão de múltiplas religiões, sincretismos, ou até uma única religião hegemônica no território" (p. 55).

Santos (2006) problematiza a questão do turismo religioso ao compará-lo com o antigo fenômeno das peregrinações. Observando a aproximação entre eles no 
sentido de que ambos ocorrem por motivações religiosas, dividem espaços tidos como sagrados e utilizam geralmente da mesma infraestrutura e dos serviços nos destinos, a distinção entre eles ficaria por conta da intensidade da motivação religiosa. No caso da peregrinação, o próprio deslocamento já é uma prática religiosa, enquanto para o turista religioso ela seria um meio para se chegar aos lugares marcados pela espiritualidade.

Em um de seus estudos sobre a geografia da religião, Rosendahl (2002) trata das peregrinações católicas e traz exemplos de alguns centros onde o aspecto turístico pode ser associado ao religioso. Para ela, contudo, as peregrinações no Brasil guardam, "na quase unanimidade dos casos, uma característica evidentemente religiosa, assumindo o sentido de sacrifício" (2002, p.04).

Tentando colocar os principais traços característicos do que se pode considerar como turismo religioso, Santos (2006) o define como:

(...) toda e qualquer deslocação (voluntária, temporária e não remunerada) religiosamente motivada, combinada com motivações de outro tipo, que tem por destino um lugar religioso (de âmbito local, regional, nacional e internacional), mas que não é em si uma prática religiosa (p. 293).

Retomando a discussão sobre a proximidade entre o turismo religioso e o cultural, a referida autora explica ainda que, como as religiões geralmente são responsáveis por grande parte da herança arquitetônica e artística criada pela humanidade, é comum a prática do turismo cultural em espaços religiosos, motivado pela intenção intelectual de se compreender o fenômeno religioso ou ainda pela busca pelo prazer estético.

A dificuldade para se distinguir as motivações dos visitantes (que podem ir além das estritamente religiosas e de outras culturais) torna-se maior, segundo a autora, quando se trata da realização das tradicionais festas religiosas que, em geral, incluem programações profanas. Nesse sentido, podemos exemplificar com o nosso objeto de estudo, o Círio de Nazaré, considerando-se inclusive a importância de se fazerem pesquisas que demonstrem em que medida o interesse principal dos visitantes tem um caráter mais voltado à espiritualidade.

Geo UERJ - Ano 15, no. 24, v. 1, $1^{\circ}$ semestre de 2013 p. 104-124

ISSN: $1415-7543$ E-ISSN: 1981-9021

http://www.e-publicacoes.uerj.br/index.php/geouerj 
A relação entre a religião e o território é abordada por Rosendahl, que em um de seus estudos, analisa a religião a partir da apropriação de determinados segmentos do espaço e afirma que "é nessa poderosa estratégia geográfica de controle de pessoas e coisas, ampliando muitas vezes o controle sobre o território que a religião se estrutura enquanto instituição" (2002, p.05). Referindo-se mais especificamente à Igreja Católica, ela observa que durante toda a sua história, a referida instituição utilizou-se consideravelmente da territorialidade em diferentes espaços. A manutenção do controle desses espaços por tanto tempo deveu-se ao seu sistema territorial hierárquico e burocrático.

A referida autora afirma que "a paróquia é sempre evocada como território principal da vida das comunidades locais" (2005, p. 01) e, em seguida, ao tratar da territorialidade religiosa, declara que "a territorialidade é fortalecida pelas experiências religiosas coletivas ou individuais que o grupo mantém no lugar sagrado e nos itinerários que constituem seu território" (p. 01).

Assim, como experiência religiosa coletiva, o Círio de Belém pode ser visto também como estratégico para a manutenção e ampliação territorial da Igreja Católica acrescentando-se ainda que, como observado por Siqueira (2012, p. 07) ao tratar do Círio de Nazaré no município de Vigia, no Estado do Pará, é possível afirmar que o Círio de Nazaré em Belém também "se enquadra numa concepção de Igreja desde a época colonial (controle, manutenção e difusão da fé católica) que na atualidade encontra-se com novas dinâmicas, entre elas a do turismo (...)". Para o referido autor, essa diversidade de dinâmicas impôs ao longo do tempo reformulações no espaço, perceptíveis na paisagem. Além disso, os diferentes interesses dos agentes envolvidos geram conflitos entre eles na gestão do espaço e, em consequência, algumas territorialidades.

Tais conflitos podem ser exemplificados em relação a manifestações como a Festa da Chiquita, realizada na Praça da República logo após a passagem da Trasladação (a qual nos referiremos a seguir), que, por ser marcada principalmente pela presença de homossexuais e simpatizantes que se divertem ao som de músicas de vários estilos, realizando-se também premiações como a "Rainha do Círio" e o "Veado de Ouro", é repudiada pela Diretoria da Festa e pelas autoridades da Igreja. 
Assim, as considerações ora apresentadas baseiam as reflexões a serem abordadas a seguir sobre o Círio de Nazaré em Belém relacionado ao processo de turistificação de espaços.

\section{O CÍRIO E O TURISMO: UM COMPLEXO DE EVENTOS E OS AGENTES NO PROCESSO DE TURISTIFICAÇÃO DO ESPAÇO}

A devoção a Nossa Senhora de Nazaré disseminou-se pelas colônias portuguesas, e no Brasil, o Estado do Pará se destaca pelos diversos municípios que a reverenciam, parte deles há mais três séculos, a exemplo da capital, Belém, que de acordo com IPHAN (2006) iniciou sua devoção por volta do ano de 1700.

Entretanto, apenas em 1793 o bispo do Pará oficializou a devoção à santa, e no mesmo ano, o então presidente da Província do Pará realizou o primeiro Círio, como pagamento de uma promessa. Esse evento é considerado atualmente como uma das maiores manifestações católicas do mundo.

Pode-se considerar que nos primeiros Círios de Nazaré em Belém destacavam-se duas romarias: a primeira conduzindo a imagem desde a sua ermida até o Palácio dos Governadores (Trasladação) e a segunda, a procissão principal, fazendo o caminho inverso. A mudança do percurso para a Igreja de Santo Alexandre, e posteriormente para a Igreja da Sé, ocorre com a posse dos republicanos, em 1891, quando o Brasil deixa de ser um Estado católico e se torna oficialmente laico, fechandose por tal razão a capela do Palácio dos Governadores (IPHAN 2006).

Atualmente a Trasladação inicia-se no Colégio Gentil Bittencourt, localizado próximo à Basílica de Nazaré (Figura 1), e conduz a imagem até a Igreja da Sé, de onde ela parte, no dia seguinte, na procissão principal, que é o Círio propriamente dito, em direção à referida basílica.

Geo UERJ - Ano 15, no. 24, v. 1, $1^{\circ}$ semestre de 2013 p. 104-124

ISSN: $1415-7543$ E-ISSN: 1981-9021

http://www.e-publicacoes.uerj.br/index.php/geouerj 


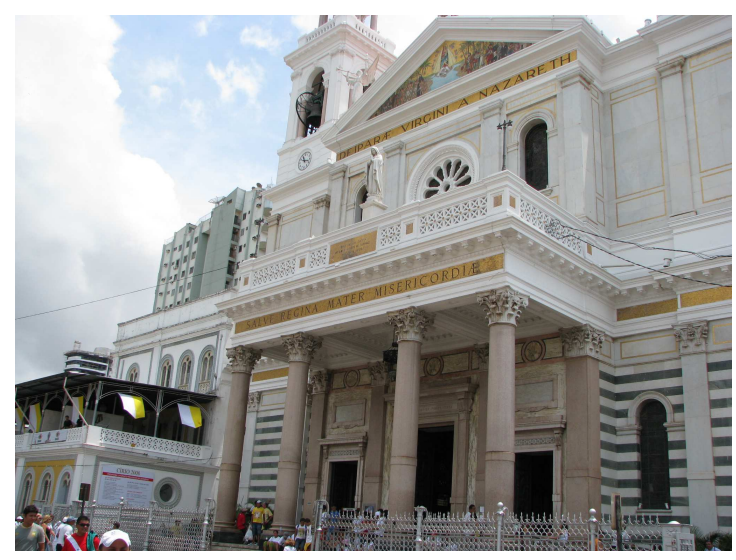

Figura 1: Basílica de Nazaré

Fonte: Costa, Marcos (2011)

Em seus mais de duzentos anos, o Círio de Nazaré em Belém tornou-se o que Alves (2005) considera como um "complexo ritual" festivo. Nesse período foram incorporadas diversas romarias, parte delas já inclusas na programação oficial do evento.

Conforme dados de IPHAN (2006) e do Portal Basílica Santuário de Nazaré, além das romarias já mencionadas, a Trasladação e a procissão principal, que ocorre no segundo domingo de outubro, são também antigas a Procissão da Festa e a do Recírio, ambas originadas no século XIX. A Procissão da Festa ocorre no quarto domingo de outubro e, diferente da maioria das festas religiosas, não é considerada a principal, sendo mais voltada às comunidades da paróquia de Nazaré. Já o Recírio ocorre no dia seguinte (segunda-feira) e é a que finaliza realmente o evento, quando a imagem é transportada da Basílica até o Colégio Gentil Bittencourt, onde fica até o ano seguinte.

A maior parte das romarias, onze oficializadas na programação do Círio, é mais recentes e foram criadas a partir da década de 1980. Essa quantidade pode ser ampliada conforme interesses de diversos grupos, a exemplo da Romaria Fluvial, a qual trataremos a seguir. Parte delas ocorre anteriormente à procissão principal e outras durante a chamada quadra nazarena, que corresponde aos quinze dias de festividade a partir da procissão principal.

Em relação à expansão territorial do Círio da sede para a Região Metropolitana de Belém, dentre as romarias oficializadas pode-se destacar o Traslado 
para Ananindeua, que ocorre desde 1992 e que a partir de 2002 envolve também o município de Marituba; a Romaria Rodoviária, que ocorre desde 1989, levando a imagem de Ananindeua para o distrito de Icoaraci, e a Romaria Fluvial, criada em 1986, que conduz a imagem de volta à sede de Belém, iniciando a Moto-romaria em direção ao Colégio Gentil Bitencourt.

A dimensão espacial das romarias que ocorrem no segundo final de semana de outubro, no qual se concentra a maior parte dos eventos, pode ser observada no mapa da Figura 2. 


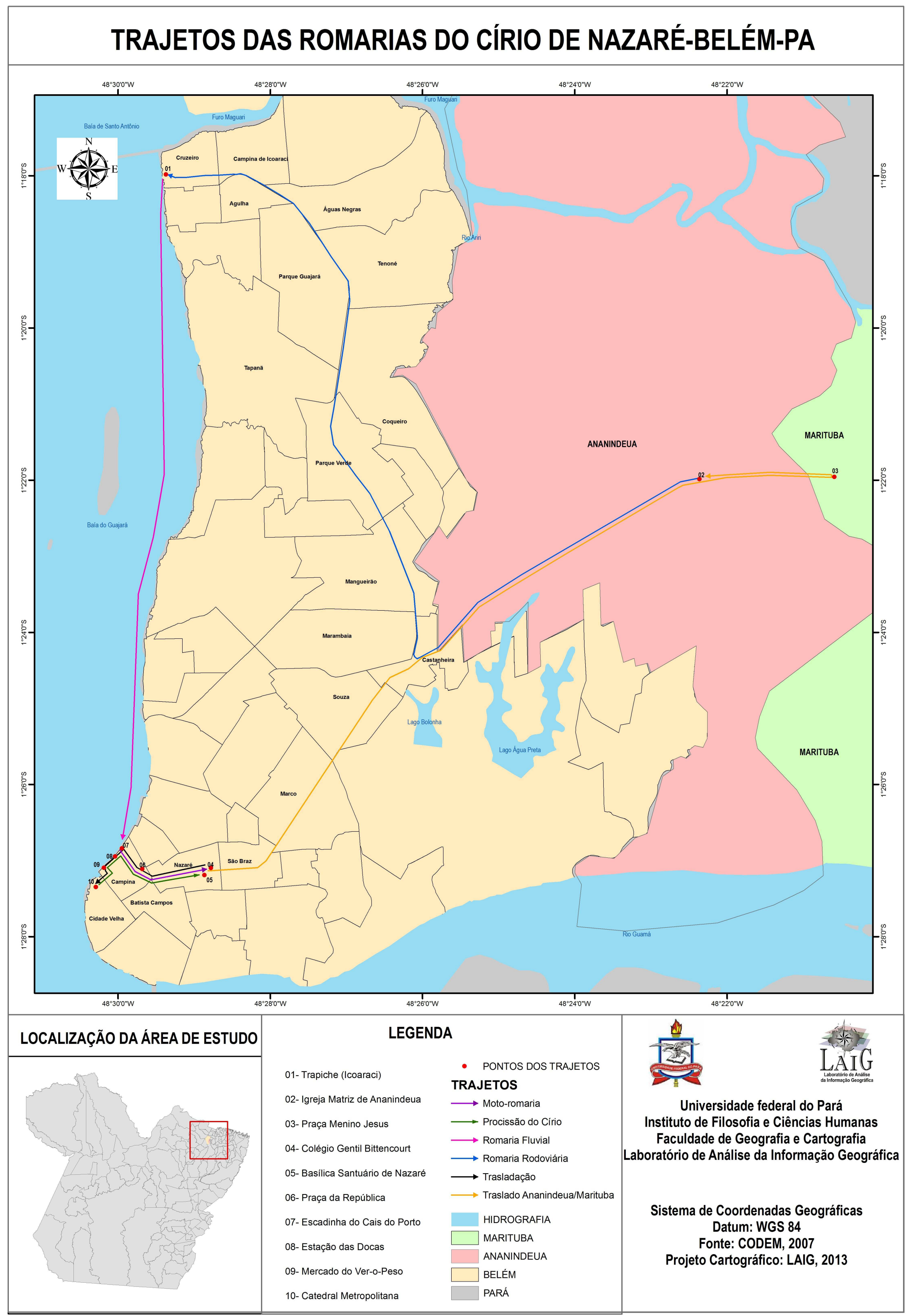

Figura 2: Trajeto das Romarias do Círio de Nazaré - Belém-PA

Geo UERJ - Ano 15, nº. 24, v. 1, $1^{\circ}$ semestre de 2013 p. 104-124 ISSN: 1415-7543 E-ISSN: 1981-9021

http://www.e-publicacoes.uerj.br/index.php/geouerj 
Geo UERJ - Ano $15, n^{\circ} .24$, v. 1, $1^{\circ}$ semestre de 2013 p. 104-124 ISSN: $1415-7543$ E-ISSN: 1981-9021

http://www.e-publicacoes.uerj.br/index.php/geouerj 
Desde sua origem, o Círio de Nazaré em Belém é um evento ligado a aspectos religiosos, políticos e econômicos, considerando-se que apesar da devoção à santa ter se iniciado por volta do ano de 1700, a primeira procissão registrada ocorreu quase cem anos mais tarde, convocada pelo governador Francisco Coutinho, que realizou durante a festa uma feira de produtos regionais, para a qual foram convidados os habitantes do interior da província (IPHAN, 2006).

Essa relação com o poder público modificou-se com a posse dos republicanos, que transformaram oficialmente o Brasil em um Estado laico. Entretanto, os governos estadual e municipal continuaram a se envolver nesse evento de forma que atualmente a contribuição do poder público em nível estadual e municipal, conforme Pantoja (2006, p.65), é considerada pela Diretoria da Festa - grupo responsável pelo conjunto de eventos mais associados aos aspectos sagrados dessa festividade - não apenas como uma forma de parceria: Prefeitura e Governo do Estado são entendidos como "entidades realizadoras".

O caráter religioso do Círio relaciona-se, em grande parte, à organização realizada pela Diretoria da Festa. Entretanto, o sagrado e o profano se complementam e nota-se a tentativa da Igreja de exercer o controle também sobre as festas profanas (PANTOJA, 2006). Além disso, destaca-se o caráter popular dessa festividade, na qual os fiéis nem sempre se subordinam ao poder da Igreja e, desta forma, tal instituição e os demais agentes devem considerá-los no planejamento e organização desse evento.

De acordo com Castro e Serra (2011), a complexidade de eventos que envolve essa festa católica, pelo menos no que se refere aos aspectos sagrados, tornou necessária a formação de um grupo que se responsabilizasse pela sua organização, papel atualmente exercido pela Diretoria da Festa. Ao fim da festividade, este grupo já inicia os preparativos para o ano seguinte. Os recursos para a realização do Círio são obtidos por meio de financiamentos dos governos estadual e municipal, bem como patrocínios de instituições públicas e privadas, e doações dos fiéis.

Quanto à atividade turística, o número de visitantes no período do Círio dinamiza diversos setores da economia paraense, sendo considerado um gerador de emprego e renda. Conforme a Tabela 1, estudos da PARATUR e do Departamento 
Intersindical de Estatística e Estudos Sócio-Econômicos - DIEESE indicam que o número de turistas que visitam Belém durante o Círio aumenta a cada ano.

\begin{tabular}{|c|c|c|}
\hline ANO & NÚMERO DE TURISTAS & GASTO PRESUMIDO \\
\hline 2010 & Cerca de 69 mil & U\$ 25 milhões \\
\hline 2011 & Cerca de 72 mil & U\$ 26 milhões \\
\hline 2012 & Cerca de 76 mil & U\$ 28 milhões \\
\hline
\end{tabular}

Tabela 1: Estimativas da participação e gastos de turistas no Círio de Nazaré em Belém (2010 a 2012)

Fonte: Paratur, 2010; Paratur, 2012 (organizada pela autora)

A atratividade turística do Círio de Nazaré em Belém perpassa tanto pela sua importância religiosa, quanto pelo seu caráter cultural e dada a importância desse evento, considerado como parte da identidade cultural não apenas dos belenenses, como dos paraenses, Figueiredo (2005) afirma que:

\footnotetext{
Nesse período, a cultura paraense manifesta-se em todos os bairros de Belém, na maioria das casas, quer pela culinária, quer pela música, artes, etc. São realizados muitos eventos em função do Círio, como feiras de artesanato, manifestações da cultura popular (bois, carimbós, etc.), exposições de arte, festas, festivais, entre outros (2005, p. 26 e 27).
}

As fachadas das casas e prédios são ornamentadas com homenagens à santa e nas proximidades da basílica são colocados arcos que demarcam a passagem de parte da procissão; ocorrem inúmeras festas profanas nesse período, além de apresentações de cantores religiosos, e são realizados um arraial com parque de diversões próximo à Basílica e uma feira de artesanato com destaque para os chamados brinquedos de miriti no bairro da Campina. Verifica-se ainda que centenas de embarcações ocupam o espaço marítimo entre o distrito de Icoaraci e a área central da sede de Belém, na Romaria Fluvial, e manifestações como o Auto do Círio (cortejo cultural realizado por artistas locais retratando o sagrado e o profano) atraem milhares de pessoas e alteram espacialmente parte do bairro da Cidade Velha.

Geo UERJ - Ano 15, nº. 24, v. 1, $1^{\circ}$ semestre de 2013 p. 104-124

ISSN: $1415-7543$ E-ISSN: 1981-9021

http://www.e-publicacoes.uerj.br/index.php/geouerj 
Assim, a concentração de manifestações culturais nesse período torna-se também um dos atrativos para os visitantes, e desta forma, acredita-se que eles são realizados também visando o aumento na geração de renda.

Este caráter cultural do Círio de Nazaré em Belém tem sido explorado pela atividade turística, o que se evidencia, por exemplo, com a instalação de arquibancadas pelo poder público para que turistas e população local possam assistir a passagem da imagem, tal como um espetáculo. Os turistas também têm a possibilidade de assistir as procissões em arquibancadas preparadas pelos hotéis localizados no percurso do Círio (FIGUEIREDO, 2005).

A própria romaria fluvial (Figura 3) é um elemento criado pela Companhia Paraense de Turismo - PARATUR, que, apesar de possibilitar aos ribeirinhos a oportunidade de fazerem suas homenagens à santa, tem sido explorada pelo trade turístico, visto que é significativa a participação de embarcações contratadas por agências de turismo, que oferecem pacotes incluindo café da manhã regional e brindes alusivos ao Círio.

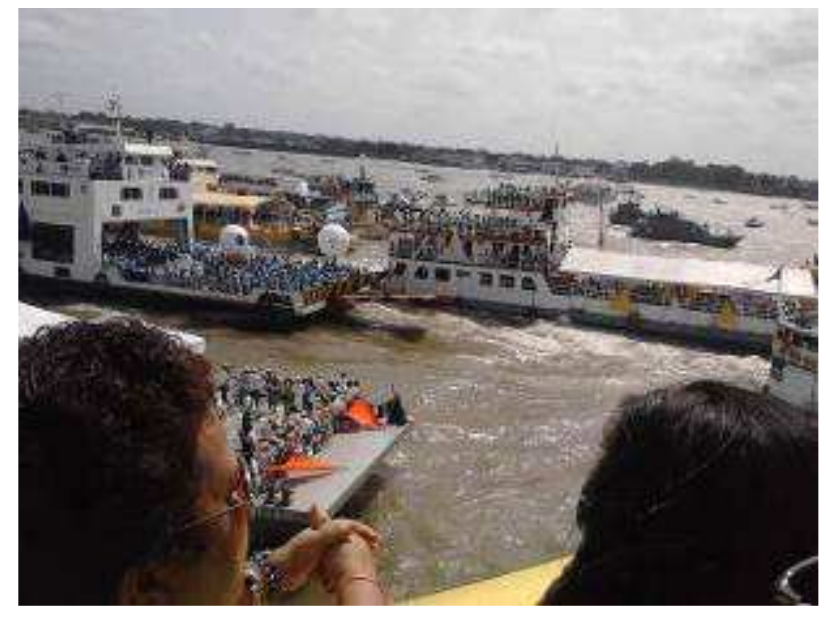

Figura 3: Romaria Fluvial

Fonte: Serra, Débora (2012)

Portanto, o processo de turistificação do espaço no Círio de Nazaré em Belém contempla diversos agentes e verifica-se que tanto o poder público, como a 
Igreja Católica e os agentes de mercado agem em parceria para tornar essa festividade mais atrativa não apenas turisticamente.

Tal parceria foi observada por Pantoja (2006) ao tratar das dimensões e dos agentes promotores da festividade no que se refere à programação oficializada pela Diretoria da Festa. Ela divide os agentes envolvidos na organização e realização do Círio entre leigos e sacerdotes. Dentre os leigos encontram-se membros do poder público, empresários patrocinadores oficiais e leigos comuns. Para ela, os possíveis interesses dos agentes são de ordem religiosa, política e/ou econômica, sendo que tais interesses não são excludentes um em relação ao outro.

Entretanto, deve-se considerar também o papel e os interesses da comunidade receptora, que ocorrem de forma heterogênea tanto por parte dela empregar-se direta ou indiretamente na atividade turística, quanto pelas suas preferências religiosas. E finalmente deve-se considerar também a própria atuação dos turistas nesse processo.

\section{CONSIDERAÇÕES FINAIS}

A abordagem territorial do turismo tem sido realizada por alguns estudiosos, principalmente da ciência geográfica. Entretanto, as políticas públicas no Brasil não têm dado a devida importância para essa questão, considerando-se que apesar da construção da Política Nacional de Ordenamento Territorial ter se iniciado em 2003, os Planos Nacionais de Turismo ainda não a tratam de forma clara.

Percebe-se também que estudos sobre o território e as territorialidades voltadas para o segmento do turismo religioso são raros especialmente no âmbito da geografia crítica, havendo um maior interesse pela geografia humanística a partir das concepções de territórios sagrados e profanos.

Desta forma, acredita-se que é necessário ampliar os estudos sobre esse segmento da atividade turística, considerando-se que ele é responsável por movimentar milhões de turistas, gerando variadas alterações espaciais e consequências positivas e negativas para diversos territórios, inclusive pela dominação material e apropriação cultural-simbólica realizada pelos seus agentes (religiosos, políticos, econômicos, entre outros). 
Quanto ao Círio de Nazaré em Belém, observa-se a necessidade, por exemplo, de levantamento de dados estatísticos mais recentes e aprofundados sobre a atividade turística decorrente da realização desse complexo de eventos sagrados e profanos. Tais dados seriam tanto em relação à quantidade de turistas, quanto à procedência e suas reais motivações que poderão auxiliar os diversos agentes promotores dessa festividade a torná-lo mais atrativo sem, contudo, espetacularizá-lo de forma a perder suas características originais ligadas à fé católica e à cultura paraense.

\section{REFERÊNCIAS}

ALVES, I. A Festiva Devoção no Círio de Nossa Senhora de Nazaré. São Paulo, Estudos Avançados, 19 (54), 2005.

BRASIL. Ministério do Turismo. Turismo Cultural: orientações básicas. 3. ed. Brasília: Ministério do Turismo, 2010.

CASTRO, N.A. R. de. O lugar do turismo na ciência geográfica: contribuições teórico-metodológicas à ação educativa. Tese (Doutorado), Universidade de São Paulo, Departamento de Geografia, Programa de Pós-Graduação em Geografia Física, São Paulo, 2006.

CASTRO, C. A. T. ; SERRA, D. R. O. Gastronomia Amazônica e Turismo na Festa do Círio de Nossa Senhora de Nazaré, em Belém do Pará - Brasil. In: Coimbra. Livro de Resumos do Congresso Internacional Turismo, Lazer e Cultura. Coimbra: Faculdade de Letras da Universidade de Coimbra, 2011. v. 01. p. 17-17.

CRUZ, Rita. Geografias do Turismo: de lugares a pseudo-lugares. São Paulo: Roca, 2007.

DECHANDT, S. G. Gestão do turismo em territórios de grande densidade religiosa: o caso do Novo México. Tese (Doutorado), Universidade Federal da Bahia, Núcleo de Pós-Graduação em Administração. Salvador: 2011

FERREIRA, L. S. Planejamento e ordenamento territorial do turismo na Região Metropolitana de Natal-RN. Dissertação (Mestrado), Universidade Federal do Rio Grande do Norte, Programa de Pós-Graduação e Pesquisa em Geografia. Natal, 2009.

FIGUEIREDO, S. L. Círio de Nazaré: festa e paixão. In: FIGUEIREDO, S. L. (ORG.). Círio de Nazaré: festa e paixão. Belém: EDUFPA, 2005.

FRATUCCI, Aguinaldo César. A Dimensão Espacial nas Políticas Públicas Brasileiras de Turismo: as possibilidades das redes regionais de turismo. Tese (doutorado em geografia). Niterói: UFF, 2008.

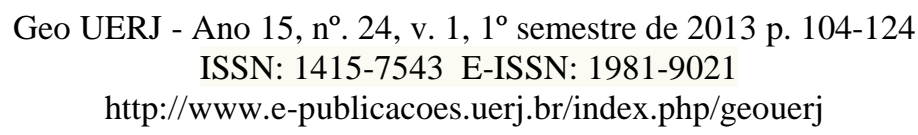


HAESBAERT, R. O mito da desterritorialização: do "fïm dos territórios" à multiterritorialidade. Rio de Janeiro: Bertrand Brasil, 2004.

INSTITUTO DO PATRIMÔNIO HISTÓRICO E ARTÍSTICO NACIONAL - IPHAN, Ministério da Cultura. Círio de Nazaré - Dossiê - Volume I, Belém, 2006.

KNAFOU, R. Turismo e Território: por uma abordagem científica do turismo. In: RODRIGUES, Adyr A.B. Turismo e geografia: reflexões teóricas e enfoques regionais. São Paulo: Ed. HUCITEC, 1996. P. 62-74

PANTOJA, V. Negócios Sagrados: reciprocidade e mercado no Círio de Nazaré. Dissertação (Mestrado), Universidade Federal do Pará, Centro de Filosofia e Ciências Humanas, Programa de Pós-Graduação em Ciências Sociais, Belém, 2006.

PARÁ. Estudos da Paratur e do Departamento Intersindical de Estatística e Estudos Sócio-Econômicos - DIEESE. Belém. 2010.

PORTAL BASÍLICA SANTUÁRIO DE NAZARÉ. Disponível em: <http://www.ciriodenazare.com.br/>. Acesso em 20 de julho de 2012.

QUEIROZ, L.M.A. A gestão pública e a competitividade de cidades turísticas: a experiência da cidade do Salvador. Tese (Doutorado), Universitat de Barcelona, Programa de Doctorado Em Planificacion Territorial Y Desarrollo Regional. Barcelona, 2005

ROSENDAHL, Z. Geografia da Religião: uma proposição temática. GEOUSP, Espaço e Tempo, São Paulo, nº 11, p. 9-19, 2002.

ROSENDAHL, Z. Território e Territorialidade: Uma perspectiva Geográfica para o Estudo da Religião. In: Com Ciência, n. 65 (Ciência e Religião), 2005. Disponível em: <http://www.comciencia.br/reportagens/2005/05/12.shtml>. Acesso em 09 de set. 2011.

RÜCKERT, A. A. O processo de reforma do Estado e a Política Nacionalde Ordenamento Territorial. In: BRASIL. Para pensar uma Política Nacional de Ordenamento Territorial. Brasília: Ministério da Integração Nacional, 2005. p. 31-39

SANTOS, M. da G. M. P. Espiritualidade, turismo e território. São João do Estoril: Principia. 2006 .

SILVA, J. A. S. Turismo, crescimento e desenvolvimento: uma análise urbanoregional baseada em cluster. Tese (doutorado), Universidade de São Paulo, Escola de Comunicações e Artes. São Paulo, 2004

SIQUEIRA, J. P. Território e Territorialidades no Espaço Turístico do Círio de Nazaré no município de Vigia-PA. $3^{\circ}$ Seminário Regional Norte e Nordeste de Pós Graduação em Geografia. João Pessoa, 2012

$$
\begin{gathered}
\text { Geo UERJ - Ano 15, no. 24, v. 1, } 1^{\circ} \text { semestre de } 2013 \text { p. 104-124 } \\
\text { ISSN: } 1415-7543 \text { E-ISSN: 1981-9021 } \\
\text { http://www.e-publicacoes.uerj.br/index.php/geouerj }
\end{gathered}
$$


SOARES, B. Turismo Paraense. Disponível em: http://turismoparaense.blogspot.com/. Acesso em: 10 de set. 2011.

SOUZA, M. J. L. de. O território: sobre o espaço e poder, autonomia e desenvolvimento. In: CASTRO, I. E. de; GOMES, P. C. da C.; CORRÊA, R. L. (Orgs.). Geografia: conceitos e temas. 11. ed. Rio de Janeiro: Bertrand Brasil, 2003.

Artigo recebido para publicação em janeiro de 2013.

Artigo aceito para publicação em maio de 2013. 